\title{
The Effect of Office Politics upon the Implementation and Management of the Job Evaluation Programme: An
} Analytical View

\author{
Muhammad Ali EL-Hajji \\ (PHD Business Administration) \\ Assistant professor, Department of management and Marketing, University of Bahrain \\ Kingdom of Bahrain \\ Email: maelhajji@hotmail.com
}

Doi:10.5296/ijhrs.v4i1.5130

URL: http://dx.doi.org/10.5296/ijhrs.v4i1.5130

\begin{abstract}
This paper concentrates on the negative office politics and negative 'office 'politicians' by simply identifying their divisive effect in context with the implementation and management of the job evaluation programme within organisations along with the difficulties that this can cause both the programme's committee or management and the employees whose jobs are to be evaluated. It does this by way of example and not because the former (office politics) is considered an exclusive phenomenon of the latter (job evaluation).
\end{abstract}

From here this paper traces the sources of power for those office 'politicians'. Simultaneously it suggests counter-measures (prophylactic and remedial) by which both the harm caused by and the virulent effect that can result from such unhealthy office politics in relation to the job evaluation programme can be inhibited or marginalized. The purpose and consequence of these counter-measures are to fortify the programme's processes and outcomes against the office political ploys and tactics.

Our experience of teaching this discipline for more than two decades with a further decade in education and the business sector is the backbone upon which this work is established.

Key words: Ethics, Inhibition of Office Politics Games, Management By Bluffing (MBB), Politics Player, Source of Power.

\subsection{Introduction}

\subsection{Definition of the Job Evaluation Programme}

A job evaluation Programme, most simply defined, is a carefully and professionally designed procedure for, and a vehicle of, performing an organization's mission and strategy that has built upon or emanated from that organization's early vision - strictly in relation to 
job evaluation philosophy for assigning a monetary value on the importance of the jobs, i.e. relating the pay rates to jobs based on the job worth / job contribution, through achieving internal pay consistency (internal pay equity) - often presented at a scheduled time. Thus, the work programme requires a high level of coordination, and a high degree of effective communication between all the parties concerned throughout all of its stages - where its acceptance is the cornerstone of its success. Once it is accepted and its results approved it will become a formal document used as a vital - systematic and impartial - instrument in establishing the organization's wage structure.

It is a prerequisite object and an imperative task particularly for those who occupy senior positions at the workplace to act ethically. This is of particular importance where the matter concerned is related to deciding work pay rates of the employees, for it directly affects their livelihood commitments and standards. This in turn puts the role or implication of the job evaluation programme under the focus and scrutiny of the individual workers, their union, management, and may well attract media attention - a thing that the workplace political games players invariably consider.

\subsection{Office Politics Defined}

The literatures of office politics show that office politics, workplace politics, workforces politics or employees / employer politics are all refer to a day- to - day organization reality and practice - through which an individual and / or group(s) within an organization put their personal interests and private agendas in advance of the organization they work for. The term 'office politics' is made of the combination of two words - office + politics - where the word 'office' is attached to the word 'politics' which in turn has become inescapable and with an invasive presence. Thus office politics is seen as a part of human nature according to Mauricio Goldstein \& Philip Read (2009: 1). In a similar but stronger statement (Rick Brandon, 2013) stated that if there is no office politics within an organization, you need to check the people's pulse because they will probably be dead. (Also in the same context see Jarie Bolander (in Daily MBA, 28 Feb. 2011). There is a strong belief in the business and management organization literatures that disregards the less pleasant side of politics and, the lack of the required knowledge and skill of forecasting the political game storms that can arise - may drive the businesses for further unpleasant practices (to be illustrated).

It is necessary to mention and to make it clear here that in highlighting negative aspects office politics alone the author in no way suggests that all office politics are negative. It is simply that the scope of this paper focuses only on the negative aspect of office politics. Thus, unless specifically stated all subsequent references to office politics should be taken as referring to negative office politics alone rather than office politics as a whole.

2 Political ethos in job evaluation

By 'politics' we mean political attitudes, manners, values and behaviour, or other forms of intervention by any individual or group (at workplace) in the affairs of job evaluation programme during any of its stages - including preparation, implementation, control, review and appeal - in order to satisfy their own purposes (and such individuals or group/s referred to as the 'office politicians'). It reflects the office politician's way 
of thinking and acting at work (individual's political ethos) that in turn reflects her or his general political ethics in the workplace. These are the office politicians, who have an expedience in, or an opportunity for making personal gains from the organization's job evaluation programme. They are that type of instigator who behaves outside the formalized systems of influence. Simply put, they are those whose behaviour is technically illegitimate (Henry Mintzberg, 1983). Hence, office politics here implies serving and pursuing self - interests as a central point. This in turn infuses an unhealthy, negative connotation upon office politics where their self-serving behaviour-replaces professional competence and endeavour. As a result their personal ambitions at work become self - focused rather than service - focused (see Robert Kreitner, 1992).

Though the motives behind the strategies of office politics might be different from one player or group to another and from one organization to another, yet they (the players) all move towards the same end-game; that is to service their own concerns through quiet, surreptitious implementation of their own hidden agenda. In practice, they hold no real consideration for the organisation's work ethic despite often appearing to show the reverse on the surface. When such office politics are levelled against the job evaluation programme, there will be deliberate distortion and manipulation instead of objectivity, impartiality and fairness. This is inevitable whenever the subjectivity co-exists with the objectivity of any sound and professional work environment. Attitudes and behaviour like these make office politics seem (at least for some people) - as if it is a taboo term associated with frustration, loathing and antagonism whenever mentioned. No surprise, therefore, to see many people with a feelling of discomfort when they hear or come cross the term office politics. To them, [ as presented in Camille Atkinson (2009 , July 28)] it seems that any thing ending with the word 'politics' will leave a bitter taste in the mouth, and yet the very word has become inescapable. Hence it is not uncommon to invarialbly notice only the negative aspects, and hence conesquences of politics.

\section{0 Looking at office politics from a specific angle}

It may be salutary here to stress that, as far as the programme of job evaluation is concerned, it is not our intention to confuse the reader by comparing the issue of office politics in the same broad sense of organizational politics where an organization is to be seen as a political entity (to be explained later). Nor are we suggesting an organization is, or should be, a political coalition where decisions are made and reached through a bargaining process as suggested by a number of writers and professionals (see Mayes and Allen, 1977). We also do not present the concept as 'management is politics' or 'politics as a control dimension in management' in organizations, as is observed by David Butcher and Martin Clarke (2001). With due respect, whilst in our view the vision of Butcher and Clarke is correct, it tends to be more pertinent to and more apparent in the domain of public administration where both administration and politics are two faces of the same coin and where the government has to bear the burdens and consequences of any work inefficiency. By contrast, in the private sector, the employer is generally more keen to keep the business away from the headaches and turmoil caused by negative internal politics - unless they serve her or 
his own interests.

Furthermore, we distinguish office politics from 'devil advocacy' (as in Charles Schwent, 1984:153-4). Devil-Advocacy is simply a legitimate method of taking a different position from a stated stand-point. Its express purpose should only be to improve the decision-making process by testing the rigour of that stand-point. [Note that Kathleen Kelley Reardon, (2003) reaches a similar conclusion when looking at office politics to describe how people influence decision-makers - though without specifically citing the term 'devil advocacy'].

The distinction between the devil advocate and the office politician is thus that the former is simply seeking to confirm that the stated position is watertight whereas the latter uses such interventions for obstructive purposes.

Similarly, we are not proposing that office politics is a ploy used to get the boss on 'your side' by applying 'mirroring' tactics. Nor are we suggesting that it is a means to impress the higher-ups by using 'bonding with your boss' tactics (see Mitchell Langbert, 2010: 1). Both 'mirroring' and 'bonding' tactics may work in different contexts other than in the professional setting of the job evaluation programme where people deal with job facts, work specifications, strict impersonal standards and criteria of evaluation. These have nothing to do with 'mirroring' or 'bonding' tactics within the meaning stated above.

Upon the aforesaid and in order to demarcate this area of research, we do not use the term 'office politics' as being synonymous or interchangeable with the term 'organizational politics' (with due respect to, for instance, Kreitner, op. cit; DuBrin: 1990). The latter is a more comprehensive and encyclopaedic term. Nor do we see the former as being equivalent or equal to the other terms mentioned above. Thus, for the purpose of this paper, we prefer to use the term 'office politics' to reflect the difference and the conflict that exists between the objectives of the job evaluation programme and the personal gains sought by the political players who use programme implementation solely to further their own self-interests.

It is, therefore, not our purpose here to discuss the issue of office politics in terms of open power relationships and conflict resolution of the work organization. Rather we deal with the term office politics in a defined or limited space and within a confined dimension. We do this simply by way of example of some aspects of the micro-politics of interaction - in relation to the job evaluation programme. (The researcher does recognise that the term of Office Politics may also apply to various organization's aspects and activities but, as stated earlier, the paper's scope focuses upon the adverse or negative effect it has upon the job evaluation programme. And this keeps abreast with our approach of the differentiating between the term office politics and the other related terms mentioned above).

\subsection{Categories of people at work - from the position of the ethics of office politics}

People at work fall into three broad categories: (a) those committed to work towards their organization's objectives (b) those induced or driven, mainly by their own needs and interests, (c) combination of the above two categories.

Care needs to be taken here not to confuse the above in general and point (b) in particular with factors such as capability. One worker may be less capable than another but 
nonetheless remain more committed to meeting the organization's objectives.

There are people at work, who are devoted and efficient, yet they are not competing for reward. Nor are they waiting to be thanked for their competency. Conversely, it is also true that there are people at work who would like to claim (or rather steal) the credit for work done by others. They are the negative office politicians who are often crafty, resourceful, skilled in public relations, with a wide networking within and without the organization, and committed to achieving their own goals, rather than the organization's needs and objectives, though they may pretend otherwise. Many of them are ready to tell lies, twist or bend the rules, distort the facts. They are opportunists. Often, they block or facilitate and endorse proposals or results according to their own whims and interests or hidden agenda. In so doing they make, if they can, the job evaluation programme less useful or fruitful instead of supporting its over-arching aim which is to produce an effective pay equity programme.

It is reasonable to expect that the worst of all worlds occurs when an office politician gets involved in the ad hoc job evaluation committee. The number of points and the weightings assigned to job factors, sub-factors, degrees or the grade level and job rate will inevitably risk becoming exposed to some degree of (negative) manipulation as a consequence.

\subsection{Sources of power for the office politician}

Furthermore, office politicians derive their power, mainly, from situations that fall into one or more of the following:

(a) When the boss is new to the position, or has less work experience, or is incompetent.

(b) When the boss is not familiar with the negative office-politicians' hidden agenda, manoeuvres, and tricks.

(c) When the boss thinks that he is doing well, and everything is running smoothly and under control; and thus he thinks that he can perform his tasks and responsibilities through managing by remote control.

(d) When the boss himself lacks a good / influential personality. This becomes even more important, when coupled with political players gaining access to confidential information of the organization regarding work resources (as, for example, in the case of HRM Department; data, information and system analysis unit; legal office; public relations office; and finance and budgetary affairs division). This can allow office politics to a more seriously influential role and effect upon the organization's policy making, strategy formation, budget direction, level and quality of the overall decisions making process that eventually affect the performance of the organizational projects, plans and activities.

(e) Similarly, when the management's work style shows an absence of harmony associated with unfairness and inequity. This situation will bring about a resistance to the job evaluation programme, empowering the political players and provide them with a virgin land to spread their seeds (rumours) even though the programme might be planned and designed professionally (adapted from Stephen Covey, 1992).

(f) When the negative office politician is a person with high / good social and/or financial status - thus taking advantage of these in serving her / his interests - more specifically when the political player is a person with PR dexterity or aptitude and interpersonal 
skills.

(g) When the (negative) office politician is experienced in job evaluation matters, but is less committed to ethical codes of practice. In this case the office politician uses all his professional knowledge and expertise to serve personal gain.

5.1 Personal relations as a mechanism for serving the office politicians' own concerns.

Office politicians are among the best people to recognise that politics, after all, is about the art and science of influencing the direction of an event, or situation, or plan / programme, or policy / strategy / decision ....etc and diverting it for attaining their own inclinations and desires. Personal relations, in their broad meaning, are an example of office politicians' mechanisms.

Once personal relations get embedded into the work of the programme, bias and nepotism or favouritism can be expected. Thus, objections to the results obtained, and appeals by the employees is a likely, albeit unfavourable, outcome. This creates an unhealthy organizational climate in which personal and professional lives of the workplace employees are not separated. Office politicians, in following their own agenda, not only take undue advantage of their own position, but also of other opportunities such as business dinners and any informal/ social gatherings and activities. They may make use of both a good intimate 'hello' on the one hand and developing a wide communications network on the other. Often, an office politician may not always lead from the front. Instead s/he might drop a rumour here, a germ of discontent there and then sit back, leaving the partisans to take such messages forward.

However, like most things in life, all political techniques and tactics are a double- edged weapon.

Sometimes, when the techniques or tactics used do not violate the applied rules and policies and their ends are justifiable from the organization's standpoint, then it turns out to be 'acceptable'. Nonetheless, it remains the case that such practice will produce winners and losers. In this case it is not the organization that suffers (or appears to suffer) but the office politician's colleagues for they are the ones who will continue to be unfairly taken advantage of. Naturally, in time the latter will come to realise that they are frequently being passed over in favour of the office politician. In such a vicious way the office politicians (i.e. those people within the work-force who instigate the divisive strategies referred to) will be the last persons accused of wrongdoing or to get blamed. I.e. Yet should their ploys, games and tactics fail they know how slip the hook by throwing them on the shoulders of other people even though they (the other people) are of the same network (usually at the low level end of the hierarchy) so that the real political game players (leading instigators) remain intact and apparently divorced from the scene. [see in this context, for example, Marilyn Haight (2013); Wikipedia... \#Aims \& Wikipedia... \#Games. For this reason the paper traces also the sources of power for office 'politicians'.

This can and often will cause resentment which in turn may have a negative impact upon the organization as a whole in the longer run. A natural result of the political games exerted is a reduction in productivity of individual employees while the concept of 'team work' or 'group working' gets negated by workplace politics (see Workplace Politics - 
Meaning and Reasons for Office Politics, presented by MSG, 2013). Office politicians look at the team work in the reverse sense, as an opportunity to strengthen their political landscape through networking or through interlocking hierarchies so as to enlarge and enrich their network towards an increasingly more influential role - often ending in collateral damage to the organization's activities and programmes. Remarkably, however, this is not always the case and simultaneously it is not uncommon for the office politician to be granted an unwritten licence by her/his colleagues to behave and act in the way that s/he does even though it is at their expense, for this may help to disclose them.

Hence, in day-to-day practice, many of the small problems or obstacles faced by the manager may have more to do with managing (the headache of) politics, than to do with their technical competencies and skills. In such a work environment one may view office politics as a corrupt, destructive factor or aberrant behaviour (Adapted from David A. Buchanan, 2008. See also in this context Yahoo vice on:

http://voices.yahoo.com/understanding-workplace-politics-america-512618.html?cat=9 ; also http://voices.yahoo.com/office-politics-good-bad-balcony-3903686.html?cat=75.)

\subsection{Different interpretations for the phenomenon of office politics}

Office politics may have different interpretations depending on the event, organizational setting, organizational culture, leadership management, managers in general, and the individual player who is the office politician. Different cultures perceive things differently. For instance, it is not surprising that Nissan, the Japanese car manufacturer, has a special code of ethics at work, according to which employees are not allowed either to give or accept any gift - directly or indirectly - in relation to their work. This stark policy is a pre-emptive procedure to prevent an office politician's ploys and tactics from adversely influencing the company's strategy and its ethical codes of practice, thereby maintaining a high degree of transparency. Others may see Nissan's gift policy as public relations. Some organisations may allow employees to accept 'reasonable' gifts but require them to be formally declared. To this, the organisation must have a clear policy (Financial Standing Orders) with a strict definition of what is reasonable and what is not. Even then, management must be vigilant and competent in overseeing the acceptance/rejection of declared gifts. Otherwise, the office politics player may be handed the opportunity to manipulate, through the back door, dissent among the workforce in suggesting that management have different rules of 'reasonableness' dependent upon who is declaring the gift.

Generally, people with (formal or informal) power, status, influence, and authority are the ideal candidates for office politicians, if they want to play this role and if the work circumstances allow. Sound logic demands that the more professional people are, the more committed they become towards the ethical code of conduct and towards the process and results of the job evaluation programme.

Perhaps due to the negative connotations and implications, many people may look at office politics unenthusiastically and thus, see it as something to be obviated. But this is the ostrich with its head in the sand approach. Conversely, others may see that you have to play the lead-role in order to avoid being played yourself - or at least be adversely affected by that which you cannot control. Office politics will not (and cannot) disappear simply because 
you do not want to recognise its existence (see also 1.2 mentioned earlier). Instead, to ensure one's own success, one must navigate the minefield of office politics. If one denies that 'bad office politics' may be going on, or avoids dealing with them, one may needlessly suffer whilst others take unfair advantage (see Mind tools Limited (2013).

\subsection{How office politics differs from human or personal judgement involved in the} process of job evaluation programme.

In addition to the above, a resort to human judgment usually applies when the criteria used (when dealing with a given activity or a concern) becomes too complex, inadequate or unreliable. It will then be down to human judgment to determine the right course of action. Such judgments, therefore, become both important and pressing. The judgment of the evaluator is concluded or presented in an 'action judgment'; as an outcome of an interaction of understanding and appreciation of the situation concerned (i.e. reality judgment); and in evaluating the situation according to standards of value (i.e. value judgment). [See for details Henry, J. (ed.) (1991) and Thompson, J. (2001)].

However, it is largely true that people's backgrounds influence their individual values, in which case evaluators bring with them their preconceived ideas of the overall relativities between jobs. This in turn may influence the rating of particular jobs (see Fonda et al., 1979: 36; Risher, H., 1984) and, because no two individuals' backgrounds can be identical, it is unlikely that any two people would put a number of jobs into the same rank order. Therefore, job evaluation, in this particular context, is a judgmental process that provides a framework within which judgment can be exercised. The evaluators then become influenced by the organization's philosophy and purpose that underpinned the original intentions for establishing the job evaluation process. Thus, objectivity may not be secured. However, neither can it be wholly removed or ignored. Hence the results that flow from the job evaluation process often show that it cannot be, to the letter, objective in all of its aspects and practices. This is especially the case when the degree of professionalism employed to undertake the process falls below required standards.

Furthermore, it is worth emphasizing that no job evaluation method or system has been developed or designed to operate in an absolutely human judgement-free-atmosphere or a bias-free setting. The difference here lies in being able to recognise which system or method used in the job evaluation programme (e.g. quantitative/analytical or qualitative) results in less bias thus making it more objective. The wider the area of human judgement involved the more office politics is active, and consequently there can only be relative outcomes. This in turn places a further emphasis upon the necessity to inhibit or arrest the spread of office politics to within manageable levels to the extent that the process and results of the job evaluation programme will not be unduly (and adversely) influenced.

However, it is generally accepted, particularly for professionals, that the compensation area (where job evaluation is an important device) is often described as the most objective domain of a subjective field.

Therefore, as the job evaluation is a human-made procedure or process, some kind of intuition or prejudgment will penetrate its outcomes and inevitably colour the evaluators' decisions or judgments (see Armstrong, 1988/1990; McBeath and Rands, 1989; 
Pritchard and Murlis, 1992). At this point a further discussion between the evaluators is needed to bridge the gap between their judgements and their professionalism in order to settle the issue(s) concerned. Fundamentally, they should be working together towards finding a suitable and fair solution - based on job facts and not on playing games of office politics designed merely to serve private or individual interests. In this context, the theory and practice of job evaluation demand the use of set standards or common criteria in order to measure and assess the job relative value. Such standards are drawn from the content and demands of the jobs themselves with a proper utilization for their respective job descriptions. This is to ensure both consistency and for maintaining job comparisons objectively (see Penny Hackett 1979). An added effect of this would be to reduce and restrict the size and the area of human judgement within the process of the job evaluation programme. [For details of what job evaluation is, and what job evaluation is not see EL-Hajji, 2012 \& 2011 respectively].

Based on this ground, the office politicians have a limited / narrow space to manoeuvre or to manipulate a professionally designed and conducted job evaluation programme. Job evaluation is not employee appraisal where managers / executives may try to gain influence through internal political actions - representing a source of bias or inaccuracy coupled with some of the Machiavellian spirit in their employees' appraisal (adapted, Longenecker, et al., 1987). Put simply, neither the mechanism nor the theory and philosophy of job evaluation allow for such deliberate practices and manipulations behind a mask of fairness, equity, objectivity and rationality.

Hence, office politics is neither synonymous with, nor an alternative to, the human judgements / human values or personal values that penetrate (in different levels or degrees) into any system of job evaluation. Both sides are different in terms of their techniques, procedures, processes and objectives.

7.0 How office politics at work produces unnecessary and unwanted challenges for management

Notwithstanding, generally, it seems that politics at work is a cross - culture value/issue, a fact of organizational life, a reality in the workplace, and therefore an inevitable phenomenon, but to different degrees and at different levels of influence in different organizations. This is another task or burden, which needs to be handled through a very careful, determined and prudent approach for those involved in the management of the job evaluation programme.

This researcher, in one of his previous jobs, recalls his superior using the term MBB, or 'Management By Bluffing', when referring to the way in which a few of his subordinates acted. He subsequently described $\mathbf{M B B}$ as the practice of decision-making (including man-management decisions) which appear to have authoritative support but which in fact have little or none. He repeatedly says that office politics players MUST not be allowed to profit from or be rewarded for their artifices or games. They have to know and learn that they can never benefit either direct or indirect from their divisive tactics or atrocity. Furthermore, it needs to be actively demonstrated that the standards of quality and professionalism set by management are such that any attempt at negative office politics will leave the instigator(s) shelterless rather than being allowed to cosily continue their antics behind the scenes. 
Otherwise, such kind of office politics behaviour would soon become a burgeoning practice that will spread throughout the workplace with the very real risk of reaching epidemic proportions - a case which will make the work of the job evaluation programme more difficult and may expose the programme to elements of ineffectiveness.

Authoritative support can take many forms which include legal ('Because the law requires it'), experience ('We've tried that before and it didn't work'), status, ('It needs to be me that goes because it is a management issue'), financial ('We can't afford it') and so on. Or it may simply be that, by employing smoke-screen tactics, the manager implies a deeper knowledge and understanding of concepts and situations about which s/he in reality knows very little about. The point being: that when such ploys are adopted, if the facts do not support the statements once they are examined under the microscope, then they are without substance and MBB has been applied - a case which will dis-serve the job evaluation programme.

Such measures may serve individual or even organizational objectives in the short-term. However, in the longer-term adverse consequences will result, particularly for the organization.

With respect to the above case, the manager in question, being senior to those operating MBB and alert to their practice, was intent on putting an end to such internal politics, albeit in a very professional and firm way. This last point is critical since he was able to demonstrate by example on how an open, professional approach will outscore MBB through the provision of an appropriate remedy for an ethical headache.

Organizations after-all, are small societies containing all their characteristics including the inherent controversial ties and diversities found within them. The importance of professionalism among the job evaluation committee members therefore cannot be over-estimated if maximum fairness and objectivity is to be achieved and the results obtained reflect the correct job value. Thus, an awareness campaign for all the parties concerned is vital if the subjective, negative impact of office politics is to be largely narrowed or repressed.

\subsection{How sometimes office politics is more harmful than either ineffectiveness or inefficiency within the work place}

Office politics is often compared to a player participating in a game who deliberately disregards its rules in order to better her/his position. Such players may cheat, mislead or make mischief. They may be dishonest in their practice. They disproportionately appeal to motives of self interest even where this means creating disharmony amongst her/his own colleagues. Strategies such as splitting people at work into opposing pockets and groups (divide and rule tactics) whilst simultaneously trying to separately maintain individual contact with each of these pockets and groups for their own future designs are commonly employed by office politicians. If it serves their purpose they may even breach organization polices, codes of practice and, not infrequently, related legislation (though, where they can they will more likely nudge others to the forefront to carry out such activities rather than put themselves directly in the limelight). They distort the facts by placing disproportionate weight upon those features that, when taken out of context, are likely to spread panic and concern among the workforce. They do not consider the full picture, preferring instead to 
work with innuendo and riddles thereby taking their audience down labyrinths of deceit designed to misinform and mislead. All this, rather than work in accordance within defined organizational objectives that provide a clear picture of their job and the boundaries laid down to them.

Thus we find that office politics (as defined in 1.2 above) is a resistive, pessimistic concept, unfavourable in appearance and one that acts negatively against the principles of organizational practice. -

With all these negative behavioural appearances, one should not find difficulty in questioning such behaviour on moral grounds alone. Nonetheless, we would pause here to consider just why such practice can only be detrimental to the organization and its work-force as a whole.

We consider that such poisonous behaviour is infective and that the organization must act swiftly if it is not to suffer the adverse consequences that will follow. Such consequences, if not successfully countered, may well prove fatal, not only to the results of the job evaluation programme, but also to the whole organization's plans and programmes or projects. Simply put, if no scrutinised decisive action is taken in time the organizational culture will eventually mutate with devastating consequences.

But just what are these consequences? It is our considered opinion that if left unchecked the organisation risks total melt-down. Admittedly, other (mis-management) factors would need to come into play before this happens. Such factors include inefficient or ill-considered management strategies, inconsistency of approach and disregard towards its work-force in general. Nonetheless, organizations that might otherwise manage to survive will be unable to do so in circumstances where office politics compounds the adverse effects of these other factors to beyond the point of no return.

As stated, we recognise that some of the organizations may be able to bear the brunt of these consequences, perhaps for quite some time, before they fail completely. They may, for example, be able to compensate the irrational utilization or wastage of appropriated resources taken from the job evaluation programme.

In any event, the point is that by the time a company experiences such conditions it is already far too late and the outcome inevitable (the only variable being whether that outcome occurs sooner or later). For these risks are not the cause of the organization's malady but instead are the symptoms of a disease encountered much earlier.

Ultimately, it is the dirty politics that negative office politicians play at work that will nail the coffin lid down. They are a product of the 'rotten apple' syndrome. A handful of such office politicians are more than enough to cripple or undermine, not only specific initiatives such as the job evaluation programme but also the work environment as a whole through the demotivation of their colleagues who had previously been energetic and creative. Yet office politics must be recognised for what it is and dealt with accordingly, for it cannot be passed over or neglected. Management are faced with a 'fight or flight' situation (see Cheock: 2008: Habit\# 1). Fight and there will be casualties. But flight will result in everyone becoming a casualty. Nonetheless, fight and only survival of the fittest (or perhaps the smartest) will prevail. Having recognized the problem and then having decided to take a stand against it management must therefore be equipped to 'play well or eat somebody 
else's dust'(Heckers 2010:1).

2014, Vol. 4, No. 1

An example of the devious practices and effects of the negative office politics is quoted (in Gautrey \& Phipps, 2008: 2) that just the cost of the time spent dealing with issues round power and politics in the UK alone is estimated at $£ 7.8$ billion a year though unnecessary and counter-productive office politicking (this did not factor in the cost of lost customers, cancelled contracts, damage to prestige or reputation, the loss of morale and the brain drain). Moreover, According to a research study by Accountemps (referred to by many writers \& commentators on office politics- e.g. Vinita Siddiqui, 2013; Michael Byrne, 2011; Dawn Rosenberg McKay, 2013) that office politics is an increasing problem. The study shows that HR professionals or administrators spend more than nine weeks out of fifty two weeks in a year (17.3\%) resolving conflicts amongst employees caused by office politics ("Surviving office politics." Talent Scout, April 16, 1998).

Office politics, therefore, paints a dismal picture of corruption within the organization, severely damaging its work-atmosphere as a consequence. The job evaluation programme is an obvious target. This is because it is installed to measure and assess job relativities with assigning a monetary value for each job- and from here comes its importance for the employees and organization alike. A whisper here and a dropped comment there may often be sufficient to inject a widespread atmosphere of suspicion and hostility against the programme. This is because a successful job evaluation programme has enough obstacles, pitfalls and thistles, not to mention the work stress, to overcome without being further burdened by those negative, office politicians who would actively seek to undermine the programme out of self-interest alone.

\subsection{Why the games of office politics are played contrary to conventional wisdom}

Conventional wisdom holds that any pressure and influence exerted by negative office politicians is contrary to the success of, in this case, the development and implementation of a successful job evaluation programme. The primary movers for such success are (and can only be) the organization's underpinning philosophy and motives. These are the factors that drive an organization into developing a job evaluation programme in the first place. By definition they are related to that organization's vision, its mission statement and its overall objectives particularly those geared towards organizational achievement and success.

Otherwise, in the absence of such a map, any job evaluation programme strategy is inevitably doomed to failure. To illustrate, as one of its main concerns, management should take every possible precaution to ensure that the whole job evaluation programme is conducted with nothing but utmost professionalism. This applies whether it is in conducting and writing job descriptions, deciding upon the benchmark jobs (key jobs) and in choosing the job factors (compensable factors). Without such professionalism, undue pressure or influence may be applied when determining the type of benchmarks or job factors that could in turn disproportionately influence the weightings (i.e. by assigning higher or lower scores / points / values in favour of specific groups of jobs such as accountants or engineers, or in favouring one group of workers over another or others such as males in comparison to females or one type of ethnic group over the rest etc). It follows that if the weightings are disproportionately applied then, inevitably, so will the final evaluation results (see also Bowey and Lupton, 1982; Edwards, P. (ed.), 1995). 
At this point, building/constructing a job evaluation programme would be no more than an intellectual exercise. Instead of achieving meaningful objectives such as the removal of wage anomalies and grievances, chaos will rein thwarting and frustrating management intentions. This in turn weakens the position of management in the eyes of employees. At that moment, the overall position reveals that the programme will have become unacceptable to the employees despite the benefits that they can expect from such programmes where they are installed to create an equitable sense of job worth across the organisation). Only if management can effectively and professionally inhibit the game-playing of any (negative) office politics may they drive the programme towards a different, more positive direction. The difficulty is, that the longer such game-playing is allowed to continue unchecked the more it becomes an uphill struggle with much momentum already lost.

\subsection{Inhibiting the game-playing of office politics}

Nonetheless, in all cases, negative office politics and its influence can largely be limited and seriously restrained. This is dependent upon the quality (professionalism and personality) of top level management and the rules and policies they apply. Timing is critical. It is like managing an accident, it needs to be dealt / treated on time. The earlier management acts, the more likely they are to succeed. But once the seeds are sown and the roots take hold the more difficult it will be to deal with the mounting antagonism that will follow. Managers should be shrewd enough to be quick on the up-take of the type of politics that office politicians are playing and the extent to which the effect their political game - plans might have in harming or influencing the progress of the job evaluation programme. This must be supplemented by an ability to find out the keys or symbols of the players and their status within the organization's workforce (adapted, Langbert, 2010). Furthermore, the manager needs to be proactive rather than reactive. Thus, in order for the manager to understand the mentality and tactics used by office politicians in dictating or playing their negative office politics, s/he needs to be knowledgeable and experienced in (handling) political games and politically heedful and acuminous so as to be ahead of the game and be able to understand more of how office politics are functioning (see Reardon, k., 2003; James, O., 2013; also see World Street Journal - Wikipedia). When the manager does so, s/he will be able to discern the art of gamesmanship from the art of management and leadership (see Goldstein \& Read, op. cit: 9). As a consequence the manager will be able to determine when office politics creates an adverse impact upon the programme's legitimate interests and objectives, thus inhibiting (or marginalizing) any negative effect.

The social, economic, financial and political fabric (and the systems contained within) can all contribute to either the growth and expansion, or the suppression and inhibition of the office politician's status and her/his role in relation to the job evaluation programme's process and outcome.

Thus, for example, organizations must always be alert to the rumours that the office politics players create and seek to spread among the employees in the workplace. They need to be aware of the job evaluation programme's advantages and, at the very least the method of evaluation used. Hence, the manager or (in larger organizations) member(s) of the management team should be constantly informing employees about decisions that will or may affect them whether directly or indirectly. Indifference, complacency, carelessness and/or 
ignorance, by contrast, will allow generated office political gossips, fiction and rumours to spread like a prairie fire throughout the organization creating an ambiguity or suspicion about the programme's objectives and competency, which in turn infuses fear and lack of confidence among the employees.

Furthermore, using the same standards or common criteria extracted from the job nature and job role (mentioned above in 6.1) simultaneously shrinks the role and influence of the games of politics over the job evaluation programme.

What make the task of inhibiting office political games more difficult for the manager concerned is that the office politics is not limited to a certain group or gender or to a specific work level. It is (as in Andrew DuBrin, p. VI) a unisex phenomenon exercised by people at all job levels, in both private and public establishments.

\subsection{Comment: Office politics in the real world - ethical theories and schools of thought}

The ethics of office politics within business is becoming of increasing interest to most sectors of the community (see Storey, J., et al., 2002; Blanchard \& Peale, 1988) due to its effects on an organization's performance, progress, its employees and its status within the market-place. This is particularly the case in the developed / industrial societies where businesses are more widespread and consequently more people are employed. Acting ethically on behalf of an organisation and the people it both employs and serves should be a must-issue. This applies at all levels of the organisation. Ideally, it would be holistic in its operation with everybody employed within the organisation (from the chief executive down to all members of the work-force) striving for the same ethical goals. Put simply this means that everyone would adopt a 'do as you would be done by' approach for the purpose of mutual benefit to all and the success of the establishment. For this to happen everyone would need to commit to the same ethical code of conduct with the primary purpose being to do right by others and, again, doing right by the organization. Unfortunately, the empirical evidence is that this is something of a utopian pipedream. This is not a pre-conceived prejudice. Rather it stems from a range of empirical attestations and corroborations (in different work settings over a very long period of service) as observed first-hand by the writer.

The office politicians, practically speaking, do not adopt any of the mainstream ethical codes of conduct when playing their games. Here the motives of self-interest are elevated to that of the free-loader (or egotism). Their sense of 'doing the right thing' now becomes 'doing the right thing by me and the rest be damned!'. Hence, for the office politician, her/his self-interests dominate and determine the type of action and the approach to be used for the sole purpose of achieving her/his own objectives. This, regardless of what sort and how much damage or harm they cause or even how unlawful that approach is.

A strong, open support and backing by management to the job evaluation panel would empower it to successfully overcome, the games or pressures applied (directly or indirectly) by office politicians. At the very least, the panel members would be given the confidence to minimize the effect of office politicians with proficiency and acumen.

This would also help members of the panel to demonstrate strong ethical values, thus maintaining the principles and standards of their work profession, which in turn would 
confirm that their entire decisions had been based upon real job facts as opposed to arbitrary conjecture (adapted Osborne \& Petheram, 2006).

Simultaneously, some aspects of the organizational learning needs to be enhanced and some aspects of the organizational culture need to be adapted, enriched and equipped with the relevant and necessary information and know-how. This is in order for the employees to become immunised and vaccinated against such types of office politics (games and rumours). As a consequence, employees would be able to differentiate between what does and what does not best serve the organization, its employees and private interest. This applies regardless of who is behind these games or pressures (be they shop-floor workers, board members or anyone in-between) for, 'in an ethical business, no one can be exempt from business discipline’ (Sternberg, 1994: 160).

Furthermore, since the presence of office politics within the workplace is an inevitable fact, and since in our view wherever it exists or is exercised it can bedevil the job evaluation programme it follows that it may create crises caused by, for example, corruption of the programme's mission. One strategy to thwart such potential game-playing is for management to encourage employees to be involved in the job evaluation program's decision making process. This will have the effect of tightening or compressing the office politician's sphere of influence. For this to be successful management needs to develop a management style and an organizational climate that embraces a democratic approach which will provide an additional source of employee programme satisfaction. Here, people (management and employees) will come together as project groups or units and taskforces to solve particular problems as and when they appear.

By stating so, this is not an invitation to engage in face - to - face challenges with the office games players or to openly deride them at the workplace. Nor is this a call to befriend them (in order to avoid their slings and arrows), Again, nor should one look to become a member of their landscape network (even though to be indirectly linked to it is unavoidable, ) for this may lead you to be manipulated by them. Keep hold of your ethical values and never throw stone against those who are difficult to cope or even agree with. Meanwhile do not hold hands with those whose attitudes are close to your own, for this would only provide ammunition for the office players who will, for example, point the finger of favouritism at you. Be a person of emotional intelligence (i.e. be aware of your self, your colleagues round you, your workplace setting and the external environment implications, specially those factors that effect or are linked to your organization's work). The more you are in a senior position the more you have to be alert and prudent.

\subsection{Conclusion: Seven issues management has to be very decisive about:}

Our reading and work experience help us to identify with confidence seven key issues that management should be able to address without having to stop and take stock of what action(s) need to be taken when faced with significant, negative events at the workplace. Nearly all of them are a cross-culture / cross-workplace phenomenon, but with varying emphases. These are:-
(a) Theft
(b) Corruption (including bribery and nepotism)
(c) Cheating 
(d) Deception (or lying)

(e) Illicit (sexual) relationship

(f) Breaching or betrayal of trust and confidence given by management

(g) Playing (negative) politics - especially when coupled with abuse of power.

Whenever or wherever malpractice and maladaptive behaviour occur within an organization, swift action is immediately required to reduce and marginalize, as far as is possible, such phenomena. The proportionate actions required may be uncomfortable ones to take. Nonetheless, management cannot afford to shy away from doing that which is right when attempting to call the organization to order. Management cannot favour adopting, developing or showing any further or greater, tolerance for any dishonourable, disorderly or problematic behaviour that can seriously vandalize or negatively influence the process and result of the job evaluation programme. This is in order for management to immunize the work of the programme with an effective antidote against the negative influence of the office politics. We are not suggesting here that management acts with a draconian rod of iron. But neither would we support the option of taking the least line of resistance. To be optimally effective the actions need to be necessary, appropriate, proportionate and equitable. Throughout the line, the manager must be committed to lawfulness, objectivity and professionalism when looking at any of these seven issues when reaching a decision. By doing so, management will add an ethical dimension to the work programme of job evaluation, which thus determines the morality of its professional actions or decisions. This is simply because, above all else, any organizational work is primarily about ethics, discipline, sincerity, a sense of responsibility and a commitment or fulfilment towards the organization's objectives.

In conducting the job evaluation programme, office politics has no fixed system or a known single model /tactic/ approach to follow. Therefore, there is no single specific and secure way that can be used against office gamesmanship (negative office politics games) in limiting or arresting the effects of those games. Different games need different but appropriate means designed to suit a particular kind of play. In this way, handling office politics can be, and should be, seen as a learning process.

All in all, this work is an attempt to provide an analytical framework of the effects and sources of negative office politics and to suggest ways of controlling the same that can prove useful for the organization and managers charged with developing a job evaluation programme. Simply put, we are concerned here with how management can make itself aware of, and be able, to inhibit and control the games of office politics in order not to influence the process, direction and outcomes of the organization's job evaluation programme.

\subsection{Epilogue - A Wake up call}

This researcher hopes that organizations do not reach a stage whereby the socio-political culture struggles or even fails in its attempts to act meaningfully against (negative) office politics. We also hope that a situation does not arise where this phenomenon is seen as a matter of coffee-shop opinion rather than being grounded in strong social, cultural, and ethical discourse. Otherwise, these will become yet further criticisms added to an already existent list of antagonism towards, and railing against, the job evaluation programme's 
mechanisms and process. Moreover, such criticisms will provide increased support for those who see or claim that being able to accurately measure the correct job values (relativities) is a myth rather than a reality (see for example Quaid, 1993).

\section{REFERENCES}

[1] Armstrong, M. (1988/1990) A Handbook of Personnel Management Practice, $3^{\text {rd }}$ ed., London: Kogan Page.

[2] Atkinson, C. (2009: July 28) Office Politics: The Good, the Bad, and the Balcony!

Link: http://voices.yahoo.com/office-politics-good-bad-balcony-3903686.html?cat=75. Accessed on 16 \& 22 Sep., 2013.

[3] Blanchard, K \& Peale, N.V. (1988) The Power of Ethical Management (You

Don't Have to Cheat to Win), London \& N. York: Heinemann Kingswood

[4] Bolander, J. (Daily MBA, 28 Feb. 2011) How to Deal with Organizational politics.

http://www.thedailymba.com/2011/02/28/how-to-deal-with-organizational-politics/

[5] Bowey, A.M. \& Lupton, T. (ed.) (1982) Handbook of Salary and Wage Systems,

$2^{\text {nd }}$ ed., Britain: Gower Publishing Company Limited.

[6] Brandon, R. (2013), Office Politics: Navigating the Political Landscape (in Women in Cable Telecommunications)

http://www.wict.org/programs/conference/schedule/Pages/Office_Politics.aspx .

Accessed on 25 Sep. 2013.

[7] Buchanan, D. A. (2008) You Stab My Back, I'll Stab Yours: Management Experience and Perceptions of Organisational Political Behaviour, British Journal of Management, Volume 19, Number 1,(March), pg 49-64).

[8] Butcher, D. and Clarke, M.. (2001) Smart Management : Using Politics in Organizations, Britain: Palgrave Publishers.

[9] Byrne, M. (2011, 22 Feb.) Surviving office politics - SME Advisor Middle East.

http://www.smeadvisor.com/2011/02/surviving-office-politics/.Accessed on 26/27 Sep. 2013.

[10] Cheok, L. (2008) 7 Habits To Win Office Politics - Lifehack, January 24.

http://www.lifehack.org/articles/management/7-habits-to-win-in-office-politics. Accessed on January 2013.

[11] Covey, S. R. (1992) Principle - centered Leadership, London: Simon \& Schuster.

[12] DuBrin, A. J. (1990) Winning Office Politics: DuBrin's Guide for 90s, USA:

Prentice-Hall, Inc.

[13] Edwards, P. (ed.) (1995) Industrial Relations Theory and Practice in Britain, U.K.:

Blackwell Publishers Ltd., reprinted 1999.

[14] EL-Hajji, M.A. (2012) Protocol of Job Evaluation: A Bird's Eye View. International Journal of Human Resource Studies (IJHRS), USA, Vol. 2, No. 1, January. 
[15] EL-Hajji, M.A. (2011) What Job Evaluation is Not: Dispelling the Doubt. International Journal of Business and Social Science, USA, Vol. 2, No. 3 (Special Issue) - January.

[16] Fonda, N., Glukich, P., Goodman, J. \& Morgan, J. (1979) 'Job Evaluation Without Sex Discrimination', Personnel Management, the Journal of the Institute of Personnel Management, Vol. 11, February, ((PP: 34-37).

[17] Gautrey, C. \& Phipps, M. (2005/2008) 21 Dirty Tricks at Work: How to Win at Office Politics - How to Beat the Game of Office Politics, England-UK: Capstone

Publishing Limited. www.amazon.co.uk/21+dirty+tricks. Accessed on 27 March, 2013.

[18] Goldstein, M. \& Read, P. (2009) Games At Work How To Recognize \&

Reduce Office Politics, USA: Jossey - Bass / A Wiley imprint. Link:

http://www.amazon.com/Games-At-

WorkRecognizePolitics/dp/0470262001\#reader_0470262001. Accessed on 17 \& 24 Sep., 2013.

[19] Hackett, P. (1979) Success In Management: Personnel, London: John Murray (Publishers) Ltd.

[20] Haight, M. (2013) Who Afraid Of The Big, Bad Boss: How to Survive 13 Types of Dysfunctional, Disrespectful, Dishonest, Little Dictators. Link:

http://www.bigbadboss.com/office- politics.html . Accessed on 18 \& 24 Sep., 2013.

[21] Heckers, J. (2010) Eight Secrets To Winning the Game of office Politics,

January 26. www.cobizmag.com/articles/eight-secrets-to-winning-the game of office politics. Accessed on Dec. 2012.

[22] Henry, J. (ed.), (1991) Creative Management, London: Sage Publications Limited. http:/blogs.hbr.org/2011/06turn-your-group-into-a-true-te. Accessed on 17 Sep. 2013.

[23] James, O. (2013) Affluenza: Office Politics - How to thrive in a world of

lying, backstabbing and dirty tricks, UK: Vermilion, an imprint of Ebury Publishing - a Random House Group company.

www.amazon.co.uk/Office-Politics-Thrive-Backstabbing-Tricks/dp/. Accessed on 28 March, 2013.

[24] Kreitner, R. (1992) Management, 5th ed., USA / London: Houghton Mifflin Company.

[25] Langbert, M. (2010) Winning office politics - A guide for 2010 and beyond, in AICPA's newsletter, Feb. 18.

www.cpa2biz.com/.../Articles_2010/Career/OfficePolitics.jsp. Accessed on Jan.

2013.

[26] Longenecker, C., Sime, H. Jr., and Gioia, D. (1987) Behind the Mask: The

Politics of Employee Appraisal, USA: The Academy of Management Executive,

Vol. 1. No.3 (PP: 183 - 193).

[27] Mayes and Allen (1977) A Conceptual Note on Organizational Politics, USA:

Academy of Management, The Academy of Management Review, Vol. 2, No. 4, 672 - 678, http://amr.aom.org/content/2/4/672.short. Accessed on October, 2012.

[28] McBeath, G. \& Rands, D. N. (1989) Salary Administration, $4^{\text {th }}$ ed., England,

U.K.: Gower Publishing Company Limited.

[29] McKay, D. R., Office Politics A Rude Intruder - in About Career 
Planning. http://careerplanning.about.com/od/workplacesurvival/a/politics.htm [30] Mintzberg, H. (1983) Power In And Around Organizations, USA: Prentice-Hall International, Inc.

[31] Mind Tools Ltd. (2013) Deal with the office Politics - Navigating the Minefield.

- Link:http://www.mindtools.com/pages/article/newCDV_85.htm. Accessed on $18,23 \& 24$ Sep. 2013.

[32] Osborne, J. and Petheram. R. (2006) Professional Ethics - Combined text,

England - UK: Osborne Books Limited

[33] Pritchard, D. and Murlis, H. (1992) Job, Roles And People, London: Nicholas

Brealey Publishing Limited.

[34] Quaid, M. (1993) Job Evaluation: The Myth of Equitable Assessment, Canada:

University of Toronto Press Incorporated.

[35] Reardon, K. K. (2003) Managing Internal politics, in Best Practice Handbook,

A Bloomsbury Reference Book, London: Bloomsbury Publishing Plc.

[36] Risher, H. (1984) Job Evaluation: Problems and Prospects, Personnel, January

- February, pp: 53-66

[37] Schwent, C. R. (1984) Devil's Advocacy in Management Decision - Making,

Journal of Management Studies, 21, April, PP. 153 - 168

[38] Siddiqui, V. (2013, August 24) Why Internal Politics Can Erode Your Work

Culture, in Employee engagement and organisation culture:

http://www.3dtalentservices.com/thought_exchange/why-internal-politics-can-erode-your-wo rk-culture/\#sthash.XkZgSXp1.dpuf. Accessed on 26 \& 27 Sep. 2013.

[39] Sternberg, E. (1994) Just Business: Business Ethics in Action, London: Little,

Brown and Company (UK) Limited.

[40] Thompson, J. L. (2001) Strategic Management, $4^{\text {th }}$ ed., London: The Thomson

Learning Logo.

[41] Yahoo! Voices: Understanding Workplace Politics in America View from the Bottom

- Presented by Yahoo! Voices:

http://voices.yahoo.com/understanding-workplace-politics-america-512618.html?cat=9.

Accessed on 16, 24 \& 28 sep. 2013.

[42] Google: Workplace Politics - Meaning and Reasons for Office Politics, presented by Management Study Group (MSG), 2008 - 2013.

https://www.google.co.uk/\#q=WorkplacePolitics-Meaning; also in:

www.managementstudyguide.com/workplace-politics.htm. Accessed on 18, 22 \& 24 sep., 2013. 